\title{
Impact of Metabolic Syndrome on Fibrosis Progression in Chronic Viral Hepatitis B Infection
}

\section{Cem Aygun*}

Department of Gastroenterology and Hepatology, Istanbul Medipol University, Istanbul, Turkey

"Corresponding author: Cem Aygun, Department of Gastroenterology and Hepatology, Istanbul Medipol University, School of Medicine, Istanbul, Turkey, Tel: +90 532 7130491; E-mail: caygun1@yahoo.com

Rec date: Mar 30, 2015, Acc date: Apr 27, 2015, Pub date: Apr 29, 2015

Copyright: @ 2015 Cem Aygun, This is an open-access article distributed under the terms of the Creative Commons Attribution License, which permits unrestricted use, distribution, and reproduction in any medium, provided the original author and source are credited.

\begin{abstract}
Many factors may increase the risk of fibrosis development in chronic viral hepatitis infections. As the burden of obesity and metabolic syndrome has been increasing in recent years, there is growing concern regarding the association between metabolic factors and chronic viral hepatitis cases. However data regarding the influence of metabolic syndrome on progression of fibrosis in chronic hepatitis B virus (HBV) infection is limited. Metabolic syndrome is a constellation of problems that includes insulin resistance, obesity, hypertension, and hyperlipidemia. Initially, epidemiologic data demonstrated that HBsAg-positive serostatus was positively correlated with a high risk of metabolic syndrome; later on, HBV was considered as a "metabolovirus" because the gene expression of HBV and key metabolic genes in hepatocytes was found to be similarly regulated. Metabolic syndrome is not only found to accelerate the progression of liver disease in patients with chronic HBV infection but also found to induce cirrhosis or even hepatocellular carcinoma development. This review article it is aimed to highlight the association of metabolic syndrome with chronic HBV infection.
\end{abstract}

\section{Introduction}

Chronic hepatitis B virus (HBV) infection is well-known as a major risk factor for liver fibrosis, cirrhosis and hepatocellular carcinoma (HCC) [1-4]. Liver fibrosis may be represented by variable clinical manifestations, which are determined by the type and extent of liver damage, the underlying liver disease and the capacity of the whole body to respond. Cirrhosis is the end stage of liver fibrosis which is characterized by architectural disruption, aberrant hepatocyte regeneration, nodule formation and vascular changes [2]. It is important to accurately predict the rate of liver fibrosis progression in patients with chronic viral hepatitis, which has important clinical significance in terms of prognostic and treatment implications [5].

Metabolic syndrome (MS) is defined as a syndrome that involves three of the following characteristics: dyslipidemia (high levels of apoB lipoproteins and triglycerides, and/or low high density lipoprotein cholesterol), an impaired fasting glucose metabolism, hypertension or central obesity [5-6]. Metabolic syndrome is directly involved in the increased prevalence of coronary heart disease, atherosclerotic diseases, and diabetes mellitus type 2 [6-8]. Other metabolic abnormalities such as liver disease, proinflammatory and prothrombotic states and sleep apnea have also been frequently reported in patients with metabolic syndrome [6-8]. The data about the influence of MS on the prognosis of patients with HBV infection remains limited. Here we tried to investigate the impact of MS on the prognosis of this special patient group.

\section{Epidemiologic link between metabolic syndrome and chronic hepatitis B infection}

The association between hepatitis $\mathrm{C}$ virus (HCV) infection with lipid and glucose metabolism was demonstrated in many studies [9-10]. Similarly, in time HBV infection was suspected to be related to dyslipidemia and metabolic syndrome. A study by Su et al. reported an association between asymptomatic chronic HBV infection and lower serum levels of total cholesterol (TC) and high-density lipoprotein cholesterol (HDL-C) [11]. In another campus-based study and with a transcriptional animal model, androgen production in HBV carriers with a low BMI $\left(<23 \mathrm{~kg} / \mathrm{m}^{2}\right)$ was found to be more triggered and upregulated HBV replication [12,13]. Several other studies reported a positive association between $\mathrm{HBV}$ infection and development of dyslipidemia and MS [14-16]. MS was also shown to cause worsening of cirrhosis in chronic HBV patients, suggesting a relationship between MS and progression of HBV infection. In a population based study chronic HBV patients diagnosed with MS had a higher HBV DNA load than patients without MS $[17,18]$.

Hyperglycemia, insulin resistance and the consequent cellular shift to an increased oxidative stress carry a higher risk of progression in chronic liver diseases. Glycated Albumin (GA) is a marker of the glycemic control during the past three weeks which is the turnover time of albumin. The GA/HbAlc ratio is predicted to be high in patients with chronic liver diseases. Indeed, the $\mathrm{GA} / \mathrm{HbA} 1 \mathrm{c}$ ratio has been reported to be associated with the histological stage of liver fibrosis and portal hypertension in HCV-positive patients and nonalcoholic steatohepatitis. The GA/HbAlc ratio is also found to be increased in association with the stage of liver fibrosis in HBV-positive patients. However, the differences among the fibrosis stages were found to be relatively small [19].

The potential link between diabetes mellitus and metabolic factors with HBV-related HCC has also aroused increasing concern. A longterm community-based cohort revealed that diabetes mellitus was associated with HBV-related HCC. Extreme obesity (body mass index $>$ or $=30 \mathrm{~kg} / \mathrm{m}^{2}$ ) was independently associated with a 4 -fold risk of HCC and there was more than 100 -fold increased risk in HBV or HCV 
Page 2 of 4

carriers with both obesity and diabetes, indicating synergistic effects of metabolic factors and chronic hepatitis [20].

This evidence suggested metabolic profiles and subsequent development of MS might be associated with chronic HBV infection. It seems vital to explore the relationship between chronic HBV and MS to inform better prevention and control strategies.

\section{Mechanisms of metabolic syndrome in chronic hepatitis B infection}

In the liver glucose, lipid and energy homeostasis is mainly regulated by peroxisome proliferator-activated receptor- $\gamma$ coactivator 1 (PGC-1 $\alpha$ ). The elevated expression of PGC-1a may alter the metabolic properties of tissues and lead to various diseases with an underlying dysregulation of metabolism, such as obesity, diabetes, neurodegeneration, and cardiomyopathy [21-24]. Several reports have suggested that HBV adopts a mode of regulation similar to major gluconeogenesis genes in the liver, such as gluconeogenic enzyme phosphoenolpyruvate carboxykinase (PEPCK) and glucose-6phosphatase (G6Pase), which are co-regulated by PGC-1 $\alpha$, HNF4a and FOXO1 [25,26]. Interestingly, PGC-1 $\alpha$ induces oxidative phosphorylation, and the expression of tricarboxylic acid cycle genes - such as SLC25A1 and ACLY-also increases the expression of the de novo fatty acid synthesis enzymes, acetyl CoA carboxylase (ACC) and fatty acid synthase (FASN) [27]. The genes involved in the biosynthesis of lipids, such as FASN and SREBP-2, are up-regulated in HBV-transgenic mouse liver [28]. In HCC, the extent of aberrant lipogenesis correlates with clinical aggressiveness, activation of the AKT-mTOR signaling pathway, and suppression of Adenosine 5'monophosphate-activated protein kinase (AMPK). In addition, the protein expression of FASN, a key enzyme of lipogenesis that is overexpressed in HCC, is known to be negatively regulated by AMPK [29]. These findings imply that aberrations of glucose and lipid metabolism are closely associated with chronic HBV infection.

\section{Effects of metabolic syndrome on fibrosis in chronic viral hepatitis $B$}

The total prognosis of HBV infected patients is directly dependent on the extent and rate of progression of fibrosis. Therefore prediction of liver fibrosis progression has a key role in the management of chronic viral hepatitis, as it will be translated into the future risk of cirrhosis and its various complications including hepatocellular carcinoma. Both hepatitis B and C viruses mainly lead to fibrogenesis induced by chronic inflammation and a continuous wound healing response. At the same time direct and indirect profibrogenic responses are also elicited by the viral infection. There are a handful of wellestablished risk factors for fibrosis progression including older age, male gender, alcohol use, high viral load and co-infection with other viruses. Metabolic syndrome is an evolving important risk factor of fibrosis progression (Table-1) [30]. In a study including $850 \mathrm{HBV}$ patients, the prevalance of MS was found to be $5 \%$. Among the components of metabolic syndrome, fasting glucose $>100 \mathrm{mg} / \mathrm{dL}$ was more frequent and MS was related to older age and higher BMI. The extent of liver fibrosis was found more serious in patients accompanying metabolic syndrome. In the study group, old age, body mass index (BMI), increased aspartate aminotransferase/alanin aminotransferase (AST/ALT), and metabolic syndrome showed association with advanced fibrosis (fibrosis stages 3 to 4 ). In multivariate analysis metabolic syndrome was found to be independently associated with liver fibrosis [31].

\begin{tabular}{|l|l|l|}
\hline Host related factors & Virus related factors & Additional factors \\
\hline Older age (>40 years) & High HBV DNA levels & Heavy alcohol consumption \\
\hline Male gender & HBV genotype(C worse than B, D worse than A) & Steatosis \\
\hline Genetic diversity & HBV variant (core promoter, pre-S) & Diabetes \\
\hline & HBV/HCV/HDV co-infection & Obesity \\
\hline & HIV co-infection & Metabolic syndrome \\
\hline HBV, hepatitis B virus infection; HCV, hepatitis C virus infection; HDV, hepatitis D virus; HIV, human immunodeficiency virus \\
\hline
\end{tabular}

Table1: Factors associated with increased risk of progression to cirrhosis [30].

Another study including 179 cases of HBV-related HCC, who were surgically treated and pathologically confirmed, showed that the higher the BMI, the higher level of insulin and homeostasis model assessment for insulin resistance (HOMA-IR) were significant risk factors for HCC development. Authors concluded that metabolic abnormalities were closely associated with the occurrence and development of HBV-related HCC [32].

A large population based study in the United States investigated the association between metabolic syndrome and risk for both primary liver cancers, hepatocellular carcinoma (HCC) and intrahepatic cholangiocarcinoma (ICC). The results indicated that pre-existing metabolic syndrome, as defined by the 2001 US NCEP-ATP III criteria, confered a statistically significant 2.13 and 1.56 fold increased risk for terminal liver diseases as HCC and ICC which was independent of other risk factors [33]. Recent data from Chinese and Korean cohorts established that MS is a risk factor of advanced liver fibrosis and cirrhosis independent of viral factors in chronic HBV infection [34,35]. In a recent prospective cohort study of $663 \mathrm{CHB}$ patients, new-onset metabolic syndrome and some of its components (namely central obesity and low high-density lipoprotein cholesterol) were found associated with liver fibrosis progression (Figure-1) $[36,37]$. Even the effect of such coincident metabolic syndrome was most apparent in the immune tolerant phase; its effect was independent of change in viral load and ALT level [36]. This is supported by the observation from a survey in general population that CHB is associated with a lower prevalence of fatty liver, hypertriglyceridemia and metabolic syndrome [37]. 


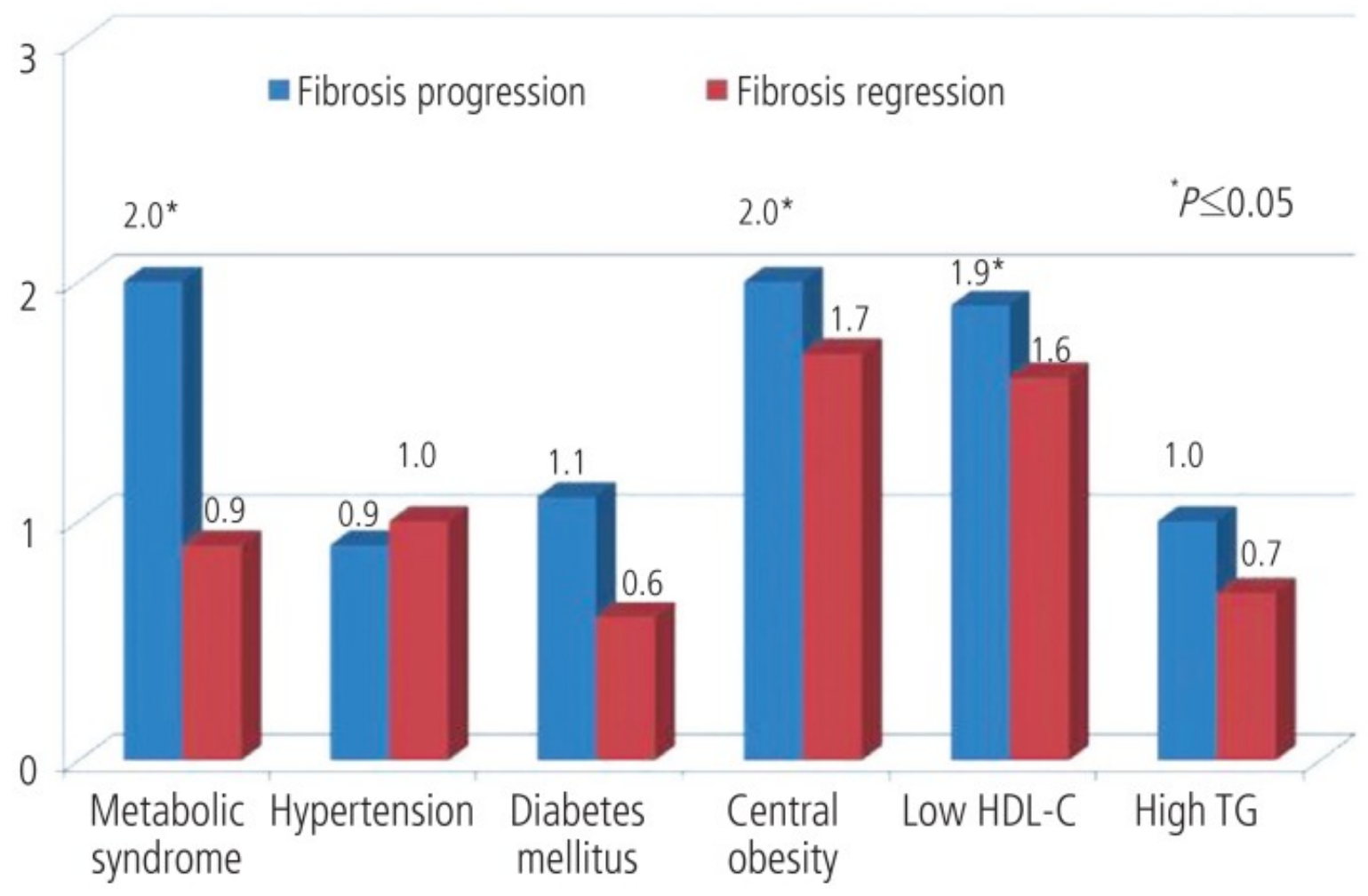

Figure 1: Adjusted odds ratio (adjusted for the change in serum alanine aminotransferase and hepatitis B virus DNA levels) of new-onset metabolic syndrome and its factors for liver fibrosis progression and regression. HDL-C high density lipoprotein cholesterol, TG triglycerides [36].

\section{Conclusion}

Obesity and the metabolic syndrome are growing epidemics worldwide. These diseases are associated with both increased risk for, and worsened outcomes of many types liver diseases as well as chronic HBV. In the liver, inflammatory and fibrogenic and angiogenic changes due to underlying insulin resistance and fatty liver disease will likely lead to increased numbers of HBV patients with cirrhosis and HCC in the near future. Much work needs to be done to define more clearly the risks for development of terminal liver disease in those with underlying metabolic syndrome. Screening those at risk, and ultimately, the suitable treatments targeting the underlying mechanisms of pathogenesis would be beneficial.

\section{References}

1. Friedman SL (2010) Evolving challenges in hepatic fibrosis. Nat Rev Gastroenterol Hepatol 7: 425-436.

2. Hernandez-Gea V, Friedman SL (2011) Pathogenesis of liver fibrosis. Annu Rev Pathol 6: 425-456.

3. Chan HL, Sung JJ (2006) Hepatocellular carcinoma and hepatitis B virus. Semin Liver Dis 26: 153-161.

4. Wong GL, Chan HL, Chan HY, Tse PC, Tse YK, et al. (2013) Accuracy of risk scores for patients with chronic hepatitis B receiving entecavir treatment. Gastroenterology 144: 933-944.

5. Gristina V, Cupri MG, Torchio M, Mezzogori C, Cacciabue L, et al. (2015) Diabetes and cancer: A critical appraisal of the pathogenetic and therapeutic links. Biomed Rep 3: 131-136.
6. Expert Panel on Detection, Evaluation and Treatment of High Blood Cholesterol in Adults.Executive Summary of The Third Report of The National Cholesterol Education Program (NCEP) Expert Panel on Detection, Evaluation, And Treatment of High Blood Cholesterol In Adults (Adult Treatment Panel III) (2001) JAMA.285: 2486-2497.

7. Dandona P, Aljada A, Chaudhuri A, Mohanty P, Garg R (2005) Metabolic syndrome: a comprehensive perspective based on interactions between obesity, diabetes, and inflammation. Circulation 111: 1448-1454.

8. Kassi E, Pervanidou P, Kaltsas G, Chrousos G (2011) Metabolic syndrome: definitions and controversies. BMC Med 9: 48.

9. Hsu CS, Liu CJ, Liu CH, Chen CL, Lai MY, et al. (2008) Metabolic profiles in patients with chronic hepatitis $\mathrm{C}$ : a case-control study. Hepatol Int 2: 250-257.

10. Huang JF, Chuang WL, Yu ML, Yu SH, Huang CF, et al. (2009) Hepatitis $\mathrm{C}$ virus infection and metabolic syndrome-a community-based study in an endemic area of Taiwan. Kaohsiung J Med Sci 25: 299-305.

11. Su TC, Lee YT, Cheng TJ, Chien HP, Wang JD (2004) Chronic hepatitis B virus infection and dyslipidemia. J Formos Med Assoc 103: 286-291.

12. Chiang CH, Lai JS, Sheu JC, Yen LL, Liu CJ, et al. (2012) The risky body mass index ranges for significant hepatitis B viral load: A campus-based study. Obes Res Clin Pract 6: e1-1e90.

13. Wang SH, Yeh SH, Lin WH, Wang HY, Chen DS, et al. (2009) Identification of androgen response elements in the enhancer I of hepatitis B virus: a mechanism for sex disparity in chronic hepatitis B. Hepatology 50: 1392-1402.

14. Huo TI, Wu JC, Lee PC, Tsay SH, Chang FY, et al. (2000) Diabetes mellitus as a risk factor of liver cirrhosis in patients with chronic hepatitis B virus infection. J Clin Gastroenterol 30: 250-254. 
15. Sangiorgio L, Attardo T, Gangemi R, Rubino C, Barone M, et al. (2000) Increased frequency of $\mathrm{HCV}$ and $\mathrm{HBV}$ infection in type 2 diabetic patients. Diabetes Res Clin Pract 48: 147-151.

16. Lao TT, Tse KY, Chan LY, Tam KF, Ho LF (2003) HBsAg carrier status and the association between gestational diabetes with increased serum ferritin concentration in Chinese women. Diabetes Care 26: 3011-3016

17. Janicko M, Senajová G, Drazilová S, Veselíny E, Fedacko J, et al. (2014) Association between metabolic syndrome and hepatitis B virus infection in the Roma population in eastern Slovakia: a population-based study. Cent Eur J Public Health 22 Suppl: S37-42.

18. Zhao J, Zhao Y, Wang H, Gu X, Ji J, et al. (2011) Association between metabolic abnormalities and HBV related hepatocelluar carcinoma in Chinese: a cross-sectional study. Nutr J 10: 49.

19. Enomoto H, Aizawa N, Nakamura H, Sakai Y, Iwata Y et al (2014). An Increased Ratio of Glycated Albumin to HbAlc Is Associated with the Degree of Liver Fibrosis in Hepatitis B Virus-Positive Patients. Gastroenterol Res Pract 2014:351396.

20. Chen CL, Yang HI, Yang WS, Liu CJ, Chen PJ, et al. (2008) Metabolic factors and risk of hepatocellular carcinoma by chronic hepatitis B/C infection: a follow-up study in Taiwan. Gastroenterology 135: 111-121.

21. Spiegelman BM, Puigserver P, Wu Z (2000) Regulation of adipogenesis and energy balance by PPARgamma and PGC-1. Int J Obes Relat Metab Disord 24 Suppl 4: S8-10.

22. Koo SH, Satoh H, Herzig S, Lee CH, Hedrick S, et al. (2004) PGC-1 promotes insulin resistance in liver through PPAR-alpha-dependent induction of TRB-3. Nat Med 10: 530-534.

23. Lin J, Wu PH, Tarr PT, Lindenberg KS, St-Pierre J, et al. (2004) Defects in adaptive energy metabolism with CNS-linked hyperactivity in PGC-1alpha null mice. Cell 119: 121-135.

24. Arany Z, He H, Lin J, Hoyer K, Handschin C, et al. (2005) Transcriptional coactivator PGC-1 alpha controls the energy state and contractile function of cardiac muscle. Cell Metab 1: 259-271.

25. Shlomai A, Shaul Y (2009) The metabolic activator FOXO1 binds hepatitis B virus DNA and activates its transcription. Biochem Biophys Res Commun 381: 544-548.

26. Finck BN, Kelly DP (2006) PGC-1 coactivators: inducible regulators of energy metabolism in health and disease. J Clin Invest 116: 615-622.

27. Bhalla K, Hwang BJ, Dewi RE, Ou L, Twaddel W et al. (2011) PGC1alpha promotes tumor growth by inducing gene expression programs supporting lipogenesis. Cancer research 71:6888-6898.
28. Hajjou M, Norel R, Carver R, Marion P, Cullen J et al. (2005) cDNA microarray analysis of HBV transgenic mouse liver identifies genes in lipid biosynthetic and growth control pathways affected by HBV. Journal of medical virology 77: 57-65.

29. Calvisi DF, Wang C, Ho C, Ladu S, Lee SA (2011) Increased lipogenesis, induced by AKT-mTORC1-RPS6 signaling, promotes development of human hepatocellular carcinoma. Gastroenterology 140:1071-1083

30. Yoon H, Lee JG, Yoo JH, Son MS, Kim DY, et al. (2013) Effects of metabolic syndrome on fibrosis in chronic viral hepatitis. Gut Liver 7: 469-474.

31. Zhao J, Zhao Y, Wang H, Gu X, Ji J, et al. (2011) Association between metabolic abnormalities and HBV related hepatocelluar carcinoma in Chinese: a cross-sectional study. Nutr J 10: 49.

32. Welzel TM, Graubard BI, Zeuzem S, El-Serag HB, Davila JA, et al. (2011) Metabolic syndrome increases the risk of primary liver cancer in the United States: a study in the SEER-Medicare database. Hepatology 54: 463-471.

33. Wong GL, Wong VW, Choi PC, Chan AW, Chim AM, et al. (2009) Metabolic syndrome increases the risk of liver cirrhosis in chronic hepatitis B. Gut 58: 111-117.

34. Yoon H, Lee JG, Yoo JH, Son MS, Kim DY, et al. (2013) Effects of metabolic syndrome on fibrosis in chronic viral hepatitis. Gut Liver 7: 469-474.

35. Wong GL (2014) Prediction of fibrosis progression in chronic viral hepatitis. Clin Mol Hepatol 20: 228-236.

36. Wong GL, Chan HL, Yu Z, Chan AW, Choi PC, Chim AM, et al. (2014) Coincidental metabolic syndrome increases the risk of liver fibrosis progression in patients with chronic hepatitis B--a prospective cohort study with paired transient elastography examinations. Aliment Pharmacol Ther 39:883-893.

37. Wong GL, Chan HL, Yu Z, Chan AW, Choi PC, et al. (2014) Coincidental metabolic syndrome increases the risk of liver fibrosis progression in patients with chronic hepatitis $\mathrm{B}-\mathrm{a}$ prospective cohort study with paired transient elastography examinations. Aliment Pharmacol Ther 39:883-893. 